\title{
Management of chronic constipation
}

\author{
Graham S Clayden
}

The management of chronic constipation in childhood has a number of problems and challenges for the paediatrician. It is seldom clear from the first contact with the child and family whether physical or psychological factors are paramount. Experience of managing a large number of such children has shown that most childrens' defaecation problems persists as a result of an intricate weave of a number of primary, secondary, physical, and psychological factors. Embarking on a single minded approach by the doctor may lead to a tightening of this knotty problem and subsequent loss of confidence and compliance. One of the objectives of this paper is to share some of this experience and define some of the features in the histories and the clinical examination which indicate the need for a particular emphasis in management.

\section{Defining the terms}

Throughout this paper the following terms are used with these meanings:

Constipation: delay in defaecation ${ }^{1}$ leading to distress (which may include anal or abdominal pain, overflow soiling, anorexia);

Soiling: the escape of stool into the underclothing;

Encopresis: : the passage of normal stools in abnormal places.

\section{General principles of management}

- Chronic constipation is important to treat in childhood because obstructive constipation in the young child will interfere with the child's physical development and overflow faecal soiling in the older child will have a destructive effect on self esteem and confidence. ${ }^{2}$ Constipation may also complicate other childhood illness especially urological and neurodevelopmental problems.

- It is important to accept that the course is likely to be protracted and subject to disappointing relapses that demoralise all those involved.

- It should be recognised that every child has an individual weave of the factors and processes that both initiate the constipation and cause it to persist.

United Medical and Dental School of Guy's and St Thomas's Hospital, St Thomas's Hospital, London SE1 7EH

Correspondence to: Dr Clayden. common with the child and family.

It is worth considering the stages in a typical case of constipation and its evolution as the child grows older:
(1) Difficulty with passing hard dry stools noted on weaning from breast to formula feeds at 6 months of age.

(2) Occasional delay of 2-3 days occurred and then the large stool was passed with considerable straining and passage of some fresh blood.

(3) Delays increased to one week or longer as child learned to avoid defaecation.

(4) Some overflow faecal soiling occurred which further irritated the anal skin.

(5) Attempts to pot train failed and parents added anger to frustration and anxiety.

(6) Fear of painful defaecation became augmented by the 'terrible $2 s$ ' with wilful rejection of parents' pleas to defaecate before the stool was so large that it hurt.

(7) The retained faecal mass in enlarged (and enlarging) rectum became physically larger than anal (and even pelvic) outlet which led to continuous soiling, hiding when sensation of imminent defaecation occurred, occasional massive but still incomplete rectal evacuation occurred and blocked the lavatory but yielded a few days of remission from soiling but reinforced the fear of defaecation due to fear of anal pain.

(8) Persistent soiling led to teasing and hostility.

(9) Recurrent failures of treatment regimens led to loss of confidence and compliance and then demands for more and more extreme treatments.

(10) Persistent failure of continence led to dissociation and the tendency to encopretic accidents even when the constipation came under reasonable control.

(11) Teenage improved vigilance and high social sanctions against incontinence increased treatment compliance and eventual improvement.

This can be considered diagrammatically with the related differential diagnosis and associated causes (fig 1).

\section{Detecting the factors}

POOR FOOD, FLUID, OR FIBRE INTAKE

Evidence for poor food, fluid, or fibre intake may be obscured by the infant appearing to be content with the feeding regimen but passing dry, hard stools as a result of the relative deficiency of fluid. A full daily intake assessment often provides evidence of poor or faddy intake. I found in surveying 488 children with constipation that $48 \%$ had some or many fads (compared with $29 \%$ in the National Child Development Survey (NCDS) ${ }^{3}$ ) and a poor appetite described in $47 \%$ (compared with 
EXTERNAL FACTORS

\begin{tabular}{|lll}
\hline $\begin{array}{l}\text { suboptimal fluid } \\
\text { and food intake }\end{array}$ & $\begin{array}{l}\text { parental stress } \\
\text { over pot training }\end{array}$ & $\begin{array}{l}\text { over soiling and parental stress } \\
\text { over soiling/encopresis }\end{array}$ \\
\hline
\end{tabular}

\begin{tabular}{|l|l|l|l|l|}
\hline \multicolumn{2}{|c|}{ anal pain } & $\begin{array}{l}\text { withholding in } \\
\text { permissively } \\
\text { large rectum } \\
\text { defaecation } \\
\text { episodes of } \\
\text { spontaneous } \\
\text { evacuations } \\
\text { and } \\
\text { soiling } \\
\text { remissions }\end{array}$ & $\begin{array}{l}\text { delayed } \\
\text { defaecation }\end{array}$ & $\begin{array}{l}\text { obstructed } \\
\text { defaecation by } \\
\text { massive stool in } \\
\text { megarectum } \\
\text { with } \\
\text { continuous } \\
\text { overflow } \\
\text { faecal soiling } \\
\text { only }\end{array}$ \\
\hline overflow soiling \\
\hline
\end{tabular}

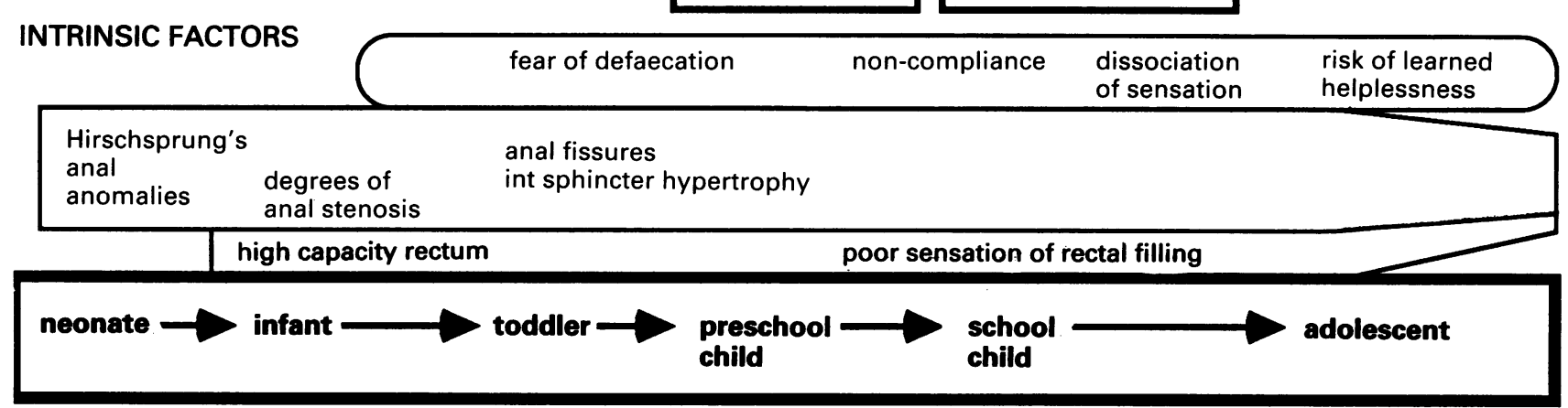

\section{INTERVENTIONS}

\begin{tabular}{|lllll|}
\hline correct feeding & $\begin{array}{l}\text { prevent } \\
\text { delayed } \\
\text { defaecation }\end{array}$ & $\begin{array}{l}\text { avoid anal } \\
\text { pain } \\
\text { accelerate } \\
\text { defaecation }\end{array}$ & $\begin{array}{l}\text { prevent faecal } \\
\text { loading } \\
\text { encourage } \\
\text { lavatory } \\
\text { abnormatines }\end{array}$ & $\begin{array}{l}\text { increase understanding } \\
\text { of physiology and } \\
\text { rationale of evacuation } \\
\text { methods and laxatives }\end{array}$ \\
\end{tabular}

Figure 1 Evolution and interaction of factors in chronic constipation in childhood.

NCDS incidence of $16 \%$ of poor appetite). Of my $47 \%$ with a poor appetite about half of these improved after they had passed their retained stool. This provides the evidence for the vicious cycle of poor intake, faecal retention, poor appetite.

CONGENITAL ABNORMALITIES OF THE ANORECTUM The aptly named Soranus recommended to the ancient Romans that all newborns should have a finger passed through the anus soon after birth to divide the anorectal membrane. ${ }^{4}$ More modern authors also support the view that anorectal rings in infancy are common. ${ }^{5}$ This invasive examination should be reserved for those babies in whom there is a suspicion in the history that a degree of obstruction is being caused. In my survey $7 \%$ of the constipated children had delay in passage of meconium in the neonatal period and $13 \%$ had passed ribbon stools. Others have reported early onset constipation due to subtle anal abnormalities that have eluded early diagnosis. ${ }^{6}$ However it is the spectre of Hirschsprung's disease which, if the diagnosis is neglected, can lead to necrotising enterocolitis or perforation, which hovers over the problem of early onset constipation. Other features which suggest that the constipation may be due to Hirschsprung's disease in addition to delay in passing meconium are: (i) failure to thrive, (ii) vomiting, (iii) appreciable abdominal distension, (iv) alternating constipation with diarrhoea, (v) an explosive gush of faecal material on withdrawing the examining finger from the rectum, and (vi) relatively little overflow faecal soiling for the degree of faecal retention in the older child (note that soiling may occur but the volume is less).

We found approximately $10 \%$ of severely protracted constipation in children referred to us initially was caused by Hirschprung's disease. ${ }^{7}$ More recently, even with increased awareness of the condition the incidence of Hirschsprung's disease in those referred is $3 \%$ and many of these children are indistinguishable from those with megarectum who have normal acetylcholinesterase staining on their suction rectal biopsy specimens.

ASSESSING THE ROLE OF ANAL PAIN

I found a history of pain on defaecation in $74 \%$, blood in the stool in 55\%, and a history of a previously diagnosed anal fissure in $17 \%$. This understandable motivation for a child to try 
their utmost to avoid defaecation, which they have learned is painful, is central to the initiation and the persistence of this cycle of problems. Anal fissure is one of many causes of painful defaecation, others include the passage of large, hard stool from the megarectum, anal soreness due to persistent soiling. Other causes are group A streptococcal perianal infection (a grossly underdiagnosed infection: every perianal skin swab we have taken in recent months when the skin has been red with evidence of purulent exudate has been positive, indicating a course of penicillin in addition to stool softeners), skin diseases (lichen sclerosis et atrophicus, epidermolysis bullosa, severe eczema (with or without milk intolerance)), and anal abuse. (Although the anal signs of abuse may be mimicked to some degree by chronic constipation it should not be forgotten that constipation can be caused by the avoidance of defaecation as a result of the anus being sore as a result of abuse. It should also be remembered that a child may perceive rectal examinations and rectally administered enemas and suppositories as abuse especially when force or coercion is used.)

\section{ASSESSING THE DEGREE OF MEGARECTUM}

Evidence which supports the theory that the child has a large capacity rectum can be obtained from detailed anorectal manometry studies on the bowel. ${ }^{89}$ These confirm the belief that chronically constipated children have high capacity rectums with relatively insensitive anorectal inhibitory reflexes even where Hirschsprung's disease has been excluded. In assessing the individual child a history of appreciable delays in defaecation, of passing massive ('lavatory blocking') stools, and a palpable mass in the abdomen are useful features. I found that $37 \%$ opened their bowels less frequently than weekly and in a half of these the delays were greater than two weeks between stools. Altogether $45 \%$ claimed to be passing only massive stools and only $14 \%$ claimed never to have produced a massive stool. Examination of the abdomen in the chronically constipated child usually demonstrates a degree of faecal loading felt central, extending up to as far as the xiphisternum in some children. I found that $25 \%$ had stool palpable but below umbilicus, $20 \%$ to the umbilicus, $21 \%$ to between the umbilicus and the xiphisternum, and $33 \%$ who had no stools palpable in the abdomen had either recently passed a 'megastool' or had soft faecal loading of their megarectum where the upper limit was not possible to define with ease. There is an important lesson to be learned from this group because failure to appreciate the degree of retention in these children, when there is overflow faecal soiling, can lead to erroneous treatments to further delay effective defaecation or lead to misdirected psychotherapy. It is with this group of soft retainers that inspection of the pattern of lower abdominal distension may give the clue to rectal loading. Here an abdominal radiograph may confirm the retained stool. Abdominal radiographs may be very valuable as an education device to reinforce the message about the faecal loading especially when the children are unable to palpate the extent of the loading themselves either because it is so soft or because they are unable to understand what they are palpating. This clear image of the retained stool goes a long way to demystifying the bowel problem and may be very helpful in the parallel psychological management.

\section{ASSESSING THE ASSOCIATED FAECAL}

INCONTINENCE

The difficulty and delay in defaecation may not trouble the child as much as the stress caused by soiling and the social response to this. Often the presenting symptom is constipation and defaecation avoidance in the preschool period but the overflow soiling increases in importance as the child approaches the years of formal schooling. In my experience it has been the soiling rather than the constipation that has fuelled the desire for further opinions on the bowel problem. It is not surprising that the average age of referral to my mainly tertiary service is 5.5 years.

The soiling frequency pattern supports the idea that soiling is mainly an involuntary escape of loose or semisolid stool around the retained stool in the megarectum. Twenty nine percent of my patients with constipation had no problem with soiling, whereas $35 \%$ soiled discontinuously (remission of soiling when the large retained stool was eventually passed), and $36 \%$ soiled continuously (probably indicating that the faecal mass in the rectum was never fully evacuated). As expected the presence of a distressing and embarassing condition such as soiling leads to or exacerbates psychological problems.

\section{ASSESSING THE PSYCHOLOGICAL FACTORS}

As summarised in fig 1 the psychological factors can be conveniently divided into the extrinsic (family and society) and intrinsic (feelings, behaviour reactions, and beliefs). The fear of defaecation is understandable when the reinforced knowledge that the activity is bound to be painful is compounded by parental pressures to conform to what they see as the most helpful and protective course. This clash of understanding and conflict of autonomy can be most easily illustrated by this dialogue:

Child: 'Every time I pooh it hurts, so I am not going to do that again'

Parent: 'You must sit there and open your bowels because if you put it off any longer it will be even more painful'

The parents' logic, although correct, is lost on the child and the tension rises. I have evidence for this in my study as $62 \%$ of the children have regularly refused to sit on the pot or lavatory and $69 \%$ of parents have at some stage in the evolution of the problem used coercion of some form (this was carried out by mothers in $60 \%$, father in $8 \%$, and both in $32 \%)$. So it can be seen how the child's fear and the parents response interact to produce another vicious cycle. When unpleasant or coercive medical management is added to this formula it is not surprising that the difficulties escalate. The use of invasive anal treatments before 
referral in my patients was $63 \%$ for suppositories and $38 \%$ for enemas.

My initial observation of the child and family at first consultation included a question to the parents on how they perceived the child's behaviour. They responded as normal or sociable $61 \%$, aggressive $13 \%$, and shy $26 \%$. My initial observation of the child gave similar figures for normality and shyness $(60 \%$ and $21 \%$ respectively) but I noted aggression in only $2 \%$ in the atmosphere of the consulting room. Psychotherapy had been or was taking place also in $15 \%$ (compared with NCDS incidence of $1 \%$ ).

In the older child the fear of defaecation seems to be eclipsed to the embarrassment and fear of exposure related to the soiling. Both these fears undermine compliance and in the older child increase the dissociation which so aggravates their elders. Another dialogue may clarify this:

Child: 'I don't need to go to the loo, I haven't soiled, and I feel fine'

Parents: 'I can smell it, go straight up and change-and don't just hide your messy pants-I found six pairs stuffed behind your radiator yesterday-you're deliberately trying to annoy me'

Child: 'I can't help it-I just want it to go away so I can be normal'

Parent: 'Just try harder to keep your pants clean, and do as you're told'

It is well worth exploring the belief scheme that the child and family have about the relationship between defaecation and soiling and where the 'trying harder' should be aimed. Providing a basic diagram of the filling rectum activating both inhibitory reflexes (which will relax the internal anal sphincter) and the sensory imput to the brain (which can initiate external sphincter responses if sensation of urgency is perceived) will help. If there is reasonable evidence of the megarectum from palpation, abdominal radiography, or even anorectal manometry the involuntary nature of overflow soiling, the likelihood of diminished rectal sensation of filling, and the difficulty of being able to pass megastools without help are readily understood. This understanding is paramount in the management of constipation at any age and supplying relevant explanatory pamphlets is helpful. ${ }^{10}$ In the adolescents it is vital as it will help them to focus on the appropriate activity (emptying the rectum fully) and exonerate them for the years of soiling with the associated guilt and blame. In the younger child a clear understanding of the factors may avoid a number of the secondary psychological problems in the child and family and aid compliance as the child understands the logic of some of the treatments which might be relatively unpleasant and time consuming.

\section{Logical treatment for constipation and its} complications

Developing a shared model of the interaction of the factors may involve consideration of many of the factors above which should be clear from a full history, examination, and perhaps abdominal radiograph. If features of Hirsch- sprung's disease are present then suction rectal biopsy for acetylcholinesterase positive nerve excess should be requested. ${ }^{11}$

Evacuation of retained faeces in the large rectum is best carried out by softening the mass sufficiently with docusate sodium (Dioctyl paediatric syrup, Medo) then using sodium picosulphate elixir (Laxoberal, Windsor or less acceptably Picolax, Ferring) as a single dose provided the faecal mass is of a size which could be physically passed through the pelvic outlet and anus. If there is doubt about this then a more prolonged course of docusate sodium with its detergent like activity may permit the picosulphate treatment later. If picosulphate is ineffective even after repeating an adequate dose further success may be achieved by using a polyethylene glycol solution such as Golytely (Seward) ${ }^{12}$ or Klean-Prep (Norgine) (although high fluid volumes are required and, if nasogastric tubes are the only effective method of administration, it would be kinder to use alternative means). If these oral methods are ineffective or impossible to administer the use of microenemas or phosphate enemas can be considered provided the child understands and can cooperate with them or can be given sufficient sedation to avoid the stress.

If the enema procedure is impossible, ineffective, or if the faecal mass is persistently too large to pass despite a lengthy course of docusate sodium, or if there are signs of acute impaction, an evacuation under a general anaesthetic should be performed. An extra benefit that can be gained from the manual evacuation under general anaesthetic is that the opportunity to perform a vigorous anal dilatation can be taken. This will weaken any increase in the activity of the internal anal sphincter (secondary to the prolonged faecal retention leading to rectal smooth muscle hypertrophy) seen on anorectal manometry. ${ }^{89}$ Once the rectum is clear from the accumulation of old stools, steps must be taken to avoid a new build up.

Maintenance treatment involves using both bulk laxatives such as lactulose or methylcellulose tablets (Celevac, Boehringer Ingelheim) as well as regular stimulant laxatives such as senna (Senokot, Reckitt and Coleman). Regular senna given once a day or alternative days is helpful in stimulating an episode of defaecation approximately 24 hours later. With a sufficient dose the reluctant child may not be able to prevent the stools from being passed and the older child may have a more complete defaecation at a convenient time for spending a period in the lavatory. Once the senna regularity is achieved it is vital that the medication is continued for long enough to avoid a relapse. In my study currently in progress, stopping active laxatives too soon is the commonest cause for relapse.

Figure 2 shows the length of time my patients have spent regularly taking stimulant laxatives. This is in agreement with traditional teaching that children with chronic constipation rarely require less than a year on stimulant laxatives.

If periods of reaccumulation occur then it is essential to repeat the evacuation procedure. It 


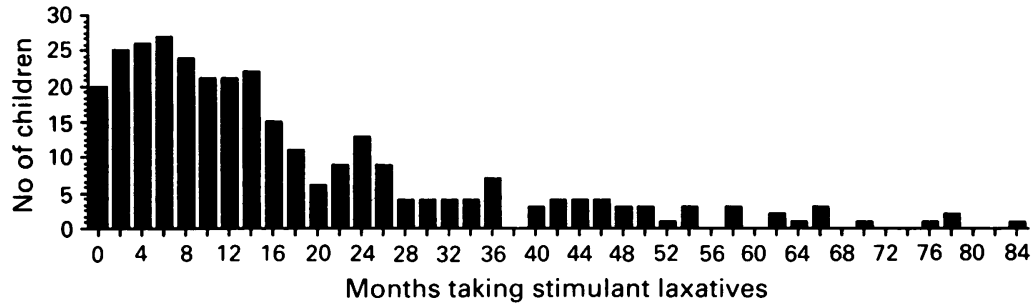

Figure 2 Duration of stimulant laxative treatment.

may be helpful in children who frequently relapse to have a boost in the laxatives by having regular weekend sodium picosulphate provided they are warned of the loose stools in advance of important social activities.

Frequent relapsers may benefit from an anal dilatation or partial internal anal sphincterotomy ${ }^{13}$ when there is evidence of internal anal overactivity. The table show some data from 230 children with severe protracted constipation treated in my clinic treated over a four year period.

It should be stressed that parallel psychological help is vital for approximately half the children presenting with protracted constipation. In children with hugely dilated megarectums other abnormalities of the myenteric plexus other than Hirschsprung's disease may be involved and this is an area of developing interest. ${ }^{14}$ Only by clear understanding of the

Data from 230 children seen over a four year period

\begin{tabular}{lc}
\hline & $\begin{array}{l}\text { No(\%) of } \\
\text { children }\end{array}$ \\
\hline Off laxatives & \\
No anal dilatation & $47(20)$ \\
Rapid response to anal dilatation & $32(14)$ \\
Slow response to anal dilatation & $58(25)$ \\
Rapid response to sphincterotomy & $7(3)$ \\
Slow response to sphincterotomy & $6(3)$ \\
Needed anal dilatation after sphincterotomy & $12(5)$ \\
Still on laxatives after four years & $28(13)$ \\
Failed to attend to complete regimen & $40(17)$ \\
\hline
\end{tabular}

abnormalities of the myenteric nerve plexi will the children with apparently untreatable constipation be clearly separated from those in whom the treatment regimen has been subtly sabotaged either as part of a Munchausen by proxy syndrome or where the family dynamics have become so dependent on the child's bowel problem that resolution of this appears too hazardous to the family members.

These two extremes facing the paediatrician demonstrate how important it is to have a correct appreciation of the factors involved in the condition as well as access to specialised teams embracing specialised paediatrics, psychiatry/psychology, surgery/histopathology, and nurse specialists when the constipation becomes complicated.

1 Weaver LT, Steiner $\mathrm{H}$. The bowel habit of young children. Arch Dis Child 1984;59:649-52.

2 Richmond J, Eddy E Garrard S. The syndrome of fecal soiling and megacolon. Am f Orthopsychiatry 1954;24: soiling and

3 Davie R, Butler N, Goldstein H. From birth to seven. The second report of the National Child Development Study. London: Longman, 1972

4 Soranus. Soranus' gynaecology. Book 2. Baltimore: Johns Hopkin Press, 1965:83-4. (Translated by O Temkin.)

5 Harris LE, Corbin PF, Hill JR. Anorectal rings in infancy: incidence and significance. Pediatrics 1953;13:59-63.

6 Kiely EM, Chopra R, Corkery JJ. Delayed diagnosis of congenital anal stenosis. Arch Dis Child 1979;54:68-70.

7 Clayden GS, Lawson JON. Investigation and management of long standing chronic constipation in childhood. Arch Dis Child 1976;51:918-23.

8 Loening-Baucke VA. Abnormal rectoanal function in children recovered from constipation and encopresis. Gastroenterology 1984;87:1299-304.

9 Clayden GS. Is constipation in childhood a neurodevelopmental abnormality? In: Milla PJ, ed. Disorders of gastrointestinal motility in childhood. Chichester: Wiley, gastroin.

10 Clayden GS, Agnarrson U. Constipation in childhood. (Information booklet for children and parents.) Oxford: Oxford mation booklet for children and par

11 Meier-Ruge W. Hirschsprung's disease: aetiology, pathogenesis and diagnosis. Curr Top Pathol 1972;59:131-79.

12 Tolia V, Fleming S, Dubois RS. Use of 'Golytely' in children olia V, Fleming S, Dubois RS. Use of 'Golytely' in children
and adolescents. $\mathcal{f}$ Pediatr Gastroenterol Nutr 1984;3: and addes $468-70$.

13 Bentley JFRC. Posterior excisional anorectal myotomy in management of chronic faecal accumulation. Arch Dis Child 1966;41:144-7

14 Scharli AF, Meier-Ruge W. Localised and disseminated forms of neuronal intestinal dysplasia mimicking Hirschsprung's disease. $\mathcal{J}$ Pediatr Surg 1981;16:164-70. 